\title{
Host-guest chemistry of anion-complexation by macrocyclic multidentate Lewis acids
}

\author{
M. Frederick Hawthorne," Xiaoguang Yang, and Zhiping Zheng \\ Department of Chemistry and Biochemistry, University of California at Los Angeles, \\ Los Angeles, California 90024, USA
}

\begin{abstract}
In contrast to the extraordinary achievements of cation complexation in host-guest chemistry, only recently has anion complexation by compounds containing electrondeficient atoms such as boron, mercury, tin and silicon received attention. We here present a new class of carborane-supported macrocyclic multidentate Lewis acid hosts which bind nucleophilic species to form isolable host-guest complexes having unprecedented structures. The synthesis and structural characterization of these complexes will be discussed along with their solution chemistry studied by ${ }^{199} \mathrm{Hg}$ NMR spectroscopy. The extension of this chemistry to the synthesis of novel supramolecular aggregates which contain the Lewis acid hosts combined with polyhedral borane anions of congruent symmetry will be discussed.
\end{abstract}

\section{INTRODUCTION}

Since the synthesis of crown ethers and discovery of their complexing properties toward alkali metal cations in 1967 (1), host-guest chemistry has developed rapidly (2) and extended to new fields of study such as supramolecular chemistry, biomimetic chemistry and materials science (3). In contrast to the extraordinary achievements of cation complexation in host-guest chemistry, only very recently has anion complexation by Lewis acid hosts received attention (4-7), even though anion-inclusion complexes were reported as early as 1968 (8a). It was first reported that halide ions can be encapsulated in "in-in" isomers of bicyclic diazaalkane hosts via electrostatic and hydrogen bond interactions (8a). Since then several protonated and charged spherical tricyclic cryptands and tricyclic tertiary ammonium cages have been synthesized as well as diprotonated planar sapphyrin $(8,9)$. These hosts bind halide ions through electrostatic interactions and/or hydrogen bonds. It is well known that intermolecular noncovalent interactions between host and guest molecules have played a central role not only in synthetic host-guest complexes (supramolecular compounds) but also in much of biomimetic and biological chemistry (10). However, systems studied so far are mainly involved with electrostatic and hydrogen bond interactions between the host and guest. Recently reported electrophilic hosts which employed boron (4), mercury (5), tin (6) and silicon (7) atoms as binding sites interact with anion guests through coordinative interactions, which offer new prospects for selective molecular recognition, anion transport and the catalytic activation of electron-rich organic and inorganic substrates. The synthesis and demonstration of Lewis acid hosts as anion recognition reagents has opened the door for the study and application of coordinative interactions in host-guest chemistry. 
Linear mercuric compounds, with two empty mercury p-orbitals, exhibit Lewis acidity towards a variety of Lewis bases and nucleophiles (11). Thus organomercury (II) compounds form anionic complexes with halides or pseudohalides in solution (12). However, no anionic complexes of this type have been previously isolated in the solid state because of their low stability. It has long been recognized that the presence of the multiple complementary interactions between host and guest are of vital importance in the stabilizing host-guest complexes (e.g. the chelate effect). It is thus not unusual that host-guest systems containing at least two binding centers have been designed and synthesized. The isolation of a stable chloride complex, $3_{2} \cdot \mathrm{Cl}^{-}$is due to the simultaneous coordination of $\mathrm{Cl}^{-}$to four atoms of mercury (5). In addition to multiple binding, the preorganization of the host plays one of the key roles in the stabilization of host-guest complexes and the macrocyclic and cryptate effects have been advanced to explain the high stability of macrocyclic and cryptate host-guest complexes (2b). These pinciples have been employed in the design of other Lewis acid hosts such as bicyclic tin hosts (6). It is obvious that the creation of preorganized multidentate Lewis acid hosts is the key to the discovery of efficient hosts which can recognize and transport anionic species. In this article, we present our recent work on the design, synthesis and structural characterization of a new class of carborane-supported macrocyclic multidentate Lewis acid hosts such as 1 and 2 (13).

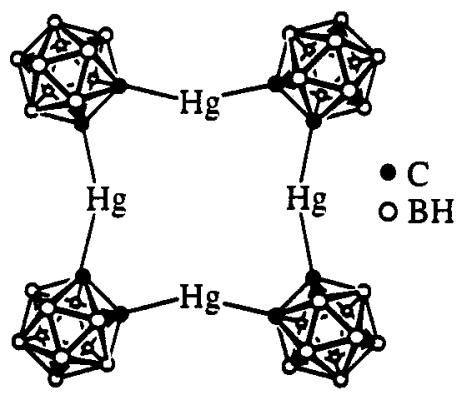

1

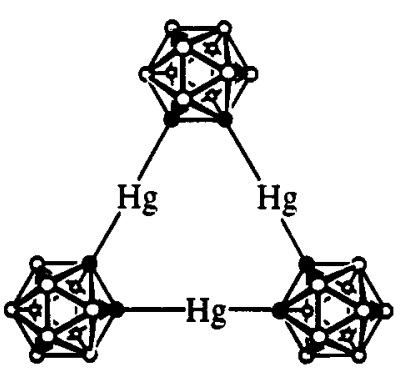

2<smiles>ClCc1ccccc1CCl</smiles>

3

\section{DESIGN AND SYNTHESIS OF MACROCYLIC MULTIDENTATE LEWIS ACID HOSTS (MERCURACARBORAND)}

To design and synthesize multidentate macrocyclic Lewis acid hosts with $\mathrm{Hg}$ (II) centers as the binding sites, we employed closo-1,2-carborane cages as supporting components for the host for two reasons. First, the closo-1,2- $\mathrm{C}_{2} \mathrm{~B}_{10} \mathrm{H}_{12}$ cage has electron-withdrawing characteristics, which greatly enhance the acidity of $\mathrm{Hg}(\mathrm{II})$ centers. For the same reason, the icosahedral carborane closo-1,2- $\mathrm{C}_{2} \mathrm{~B}_{10} \mathrm{H}_{12}$ can be easily lithiated by $n-\mathrm{BuLi}$ at the carbon positions to give closo-1,2- $\mathrm{Li}_{2}-1,2-\mathrm{C}_{2} \mathrm{~B}_{10} \mathrm{H}_{10}$ (14), which facilitates the desired synthesis. The reaction of mercury (II) halides with closo-1,2- $\mathrm{Li}_{2}-1,2-\mathrm{C}_{2} \mathrm{~B}_{10} \mathrm{H}_{10}$ results in the formation of the host-guest species, $1 \cdot X L i\left(X=\mathrm{Cl}^{-}, \mathrm{Br}\right)$ or $1 \cdot \mathrm{I}_{\mathbf{n}} \mathrm{Li}_{\mathrm{n}}(\mathrm{n}=1,2)(13 \mathrm{a}, \mathrm{b})$. When $\mathrm{Hg}(\mathrm{OAc})_{2}$ is employed in a similar reaction, trimeric 2 is formed (13d), as shown in Scheme 1.

Macrocyclic multidentate Lewis acid host 1 is a charge-reversed analogue of [12]crown-4 with a preorganized structure. Similarly, 2 is the electrophilic analogue of [9]-crown-3. The synthesis of halide ion compplexes of [12]mercuracarborand-4 is significant because it efficiently produces a 
macrocyclic multidentate Lewis acidic host, 1, in a single step. It is believed that halide ions function as templates which direct the assembly of the host macrocycle, since cyclic trimer $\mathbf{2}$ is formed only in

Scheme 1

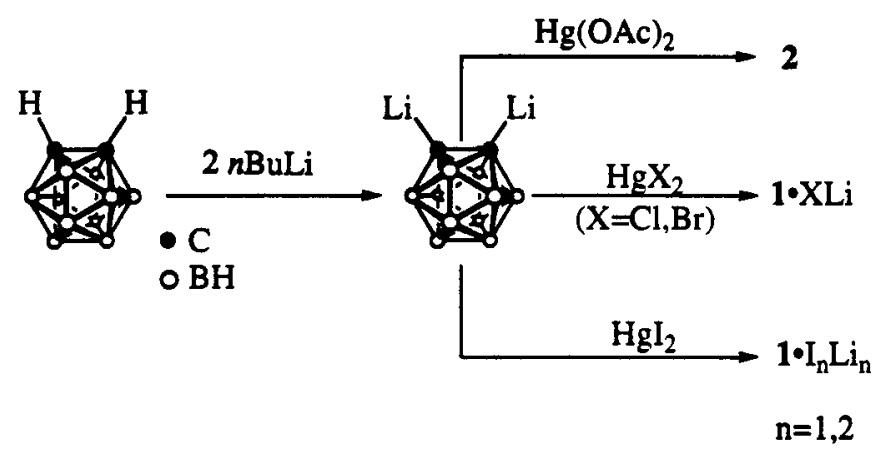

the absence of halide ion (Scheme 1). Therefore, the formation of cyclic trimer (2) must be more kinetically favorable over the formation of the tetramer (1) in the absence of template species. It is also observed that the reaction of closo-1,2- $\mathrm{Li}_{2}-1,2-\mathrm{C}_{2} \mathrm{~B}_{10} \mathrm{H}_{10}$ with mercuric halides gives higher yields of cyclic tetramer than the similar reaction with $\mathrm{HgOAc}$ gives cyclic trimer. The presence of halide ions held within the cyclic tetramer further strengthens the claim that halide ions exercise a template effect in the formation of mercuracarborand cycles. The template effect of metal ions in promoting certain cyclization reactions have been widely recognized (15).

$\mathrm{X}$-ray diffraction studies of $1 \cdot \mathrm{ClLi}$ and $1 \cdot \mathrm{I}_{2}\left(\mathrm{AsPh}_{4}\right)_{2}$ revealed the component halide ions are tetra-coordinated by four mercury atoms as shown in Figure 1 and 2, respectively. Chloride ion is almost complete inside the cavity of the cyclic host. and the $\mathrm{Hg}-\mathrm{Cl}$ distance of 2.944 (2) $\AA$ is significantly shorter than the van der Waals distance (16). Iodide ion is too large to enter the cavity of 1 and an iodide ion is located both above and below the host plane with $\mathrm{Hg}$-I distances ranging from 3.277 to $3.774 \AA$. The location of $\mathrm{Cl}^{-}$in 1 maximizes the cooperative interaction of four empty mercury p-orbitals with two filled p-orbitals of the chloride ion. The chloride ion is therefore bound to four mercury atoms via two $3 \mathrm{c}-2 \mathrm{e}$ bonds, as is each of the iodide ions in 1. $\mathbf{I}_{2}^{2-}$.

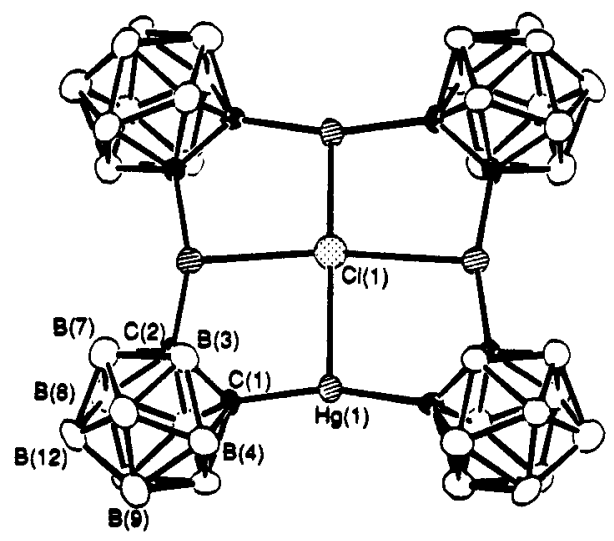

Fig. 1 The molecular structure of $1 \cdot \mathrm{Cl}^{-}(13 \mathrm{a})$.

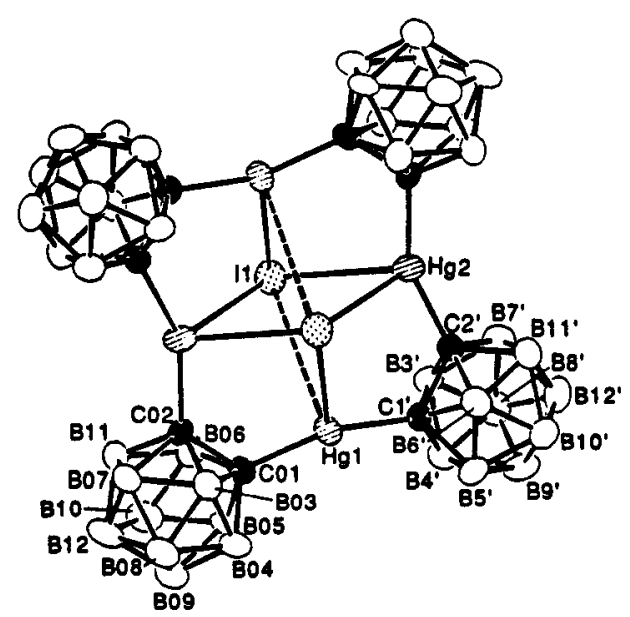

Fig. 2 The molecular structure of $1 \cdot I_{2}^{2-}(13 b)$. 
The trimeric cycle, 2 , also binds halide ions and basic organic solvents such as tetrahydrofuran and acetonitrile. The chloride ion complex is obtained by the addition of $\mathrm{LiCl}$ in $\mathrm{H}_{2} \mathrm{O}$ to an etheral solution of $\mathbf{2}$ and $\mathrm{LiCl}$ is extracted from the aqueous phase to the organic phase upon formation of 2.CILi. The species, $2 \cdot \mathrm{Cl}$ - could be detected by negative ion FAB mass spectroscopy. Because of the linearity of mercury coordination in $\mathbf{2}$, it is possible for $\mathbf{2}$ to coordinate more than two centrally bound molecules of acetonitrile. The structures of $2 \cdot\left(\mathrm{CH}_{3} \mathrm{CN}\right)_{5}$ and $2 \cdot\left(\mathrm{CH}_{3} \mathrm{CN}\right)_{3}$ are shown in Figure 3.
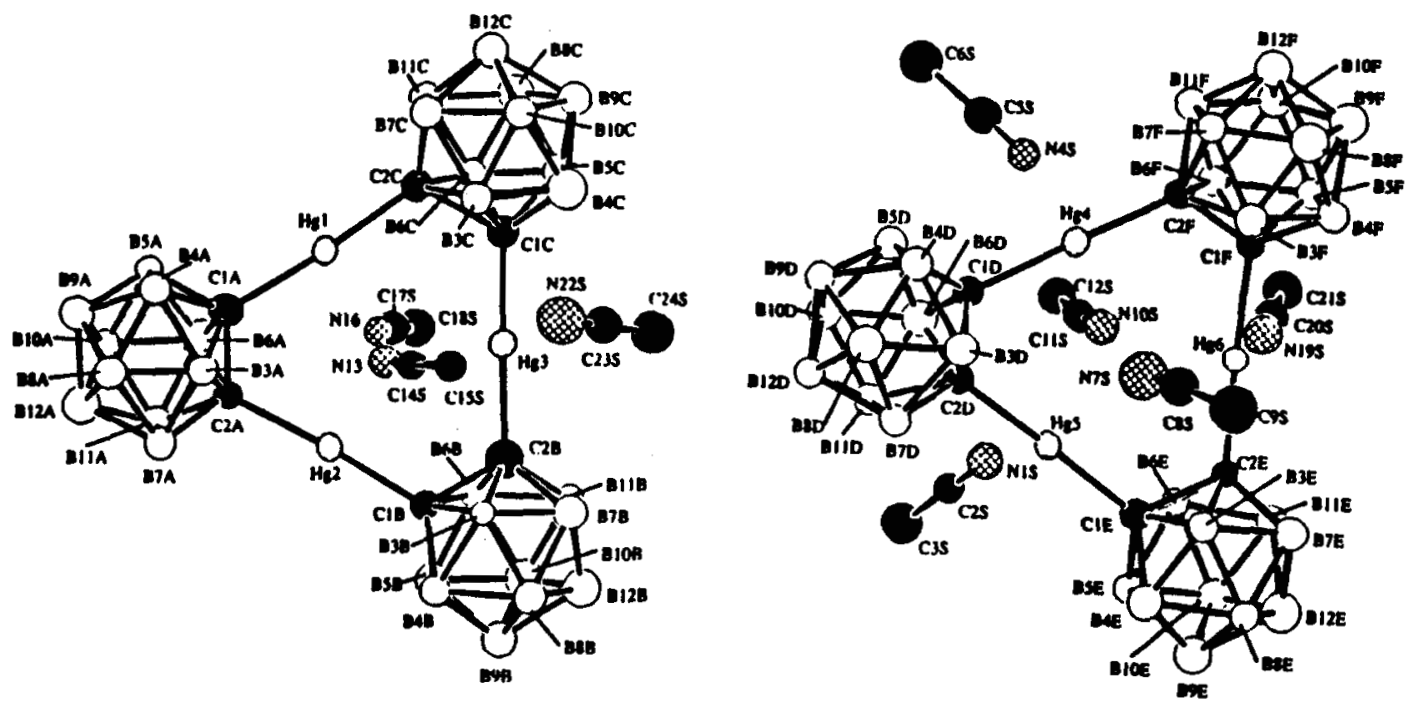

Fig. 3 The structures of $2 \cdot\left(\mathrm{CH}_{3} \mathrm{CN}\right)_{3}(\mathrm{~A})$ and $2 \cdot\left(\mathrm{CH}_{3} \mathrm{CN}\right)_{5}(\mathrm{~B})(13 \mathrm{~d})$.

Since only halide ion complexes of 1 were isolated as reaction products, the question arose regarding the possible stability of 1 in the absence of halide ions. It was subsequently found that 1. $\mathrm{I}_{2} \mathrm{Li}_{2}$ reacted with $\mathrm{AgOAc}$ to give 1 and insoluble Agl. Species 1 crystallized from THF as 1.(THF) 4 and its structure is shown in Figure 4. The buckled conformation of 1 facilitates the coordination of THF to the mercury centers and the mercury primary coordination in 1 is less distorted from linearity than in its halide ion complexes.

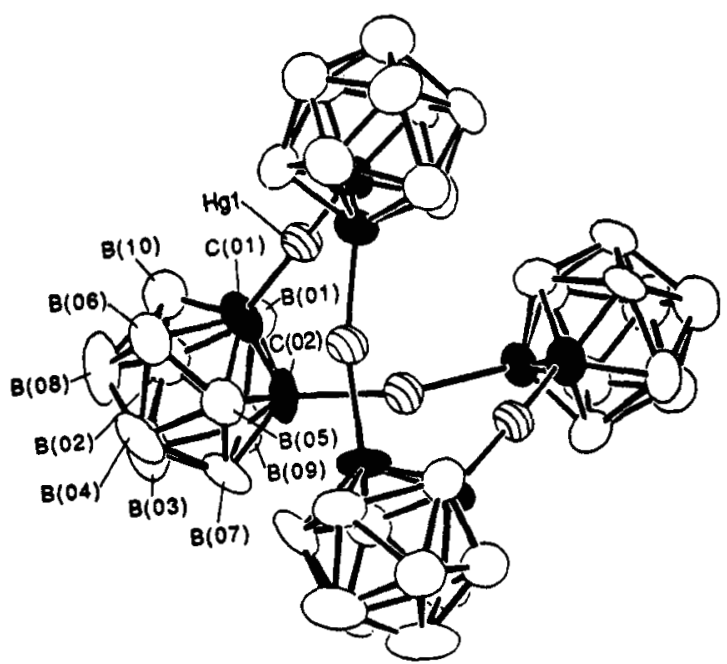

Fig. 4 The molecular structure of $1 \cdot(\mathrm{THF})_{4}$ with $\mathrm{THF}$ molecules removed for clarity. 
Scheme 2
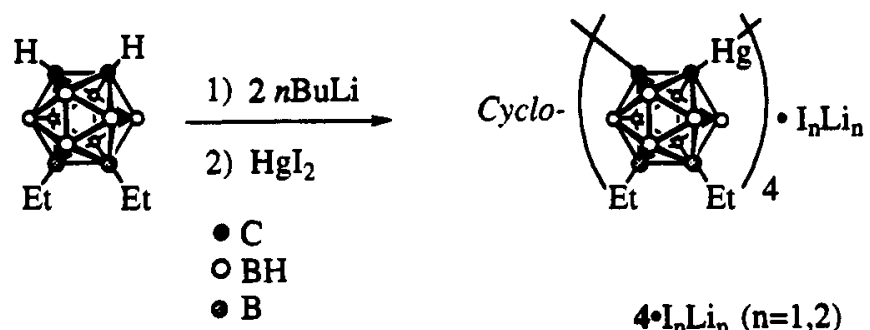

Scheme 3
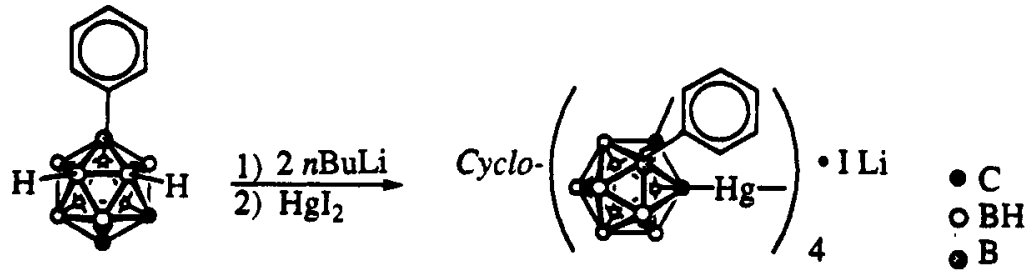

The [12] mercuracarborand-4, 1, is soluble in most electron-donor solvents and it coordinates with these solvent molecules, thus mitigating its potential usefulness in the homogeneous catalysis of organic reactions. In order to elimilnate this competitive binding of solvent molecules, we have synthesized the octaethyl derivative of [12]mercuracarborand-4 (4) as shown in Scheme 2. The species 9,12-Et2-1,2- $\mathrm{C}_{2} \mathrm{~B}_{10} \mathrm{H}_{10}$ can be lithiated easily and the resulting dilithio species reacts with $\mathrm{HgI}_{2}$ to form $4 \cdot \mathrm{I}_{2} \mathrm{Li}_{2}$ and $4 \cdot \mathrm{Ii}$ in a 2:1 ratio. We have also prepared 3-phenyl substituted carborane and the corresponding iodide ion complex of the tetrameric cycle, 5.ILi (13f) (Scheme 3). The formation of tetrameric cycles appears to be universal with derivatized carboranes. These derivatized host-guest complexes all exhibit higher solubilities than those of 1 . The mercuracarborand, 4 , obtained from the reaction of $\mathrm{AgOAc}$ with $4 \cdot \mathrm{I}_{2} \mathrm{Li}_{2}$, is an air-stable white solid and soluble in benzene, toluene, chloroform and methylene chloride. When 4 crystallizes from $\mathrm{CHCl}_{3}$, solvent molecules are not coordinated to 4 , as revealed by X-ray diffraction analysis. Like $1 \cdot(\mathrm{THF})_{4}, 4$ has a buckled structure as shown in Figure 5. In principle, four structural isomers of 5 could be formed with phenyl substitutents arrayed about the periphery of the host cavity. The isomer 5.ILi shown in Figure 6, is the only product isolated from the reaction of closo-1,2- $\mathrm{Li} 2-3-\mathrm{Ph}-1,2-\mathrm{C}_{2} \mathrm{~B}_{10} \mathrm{H}_{9}$ and $\mathrm{HgI}_{2}$, as observed by HPLC. This

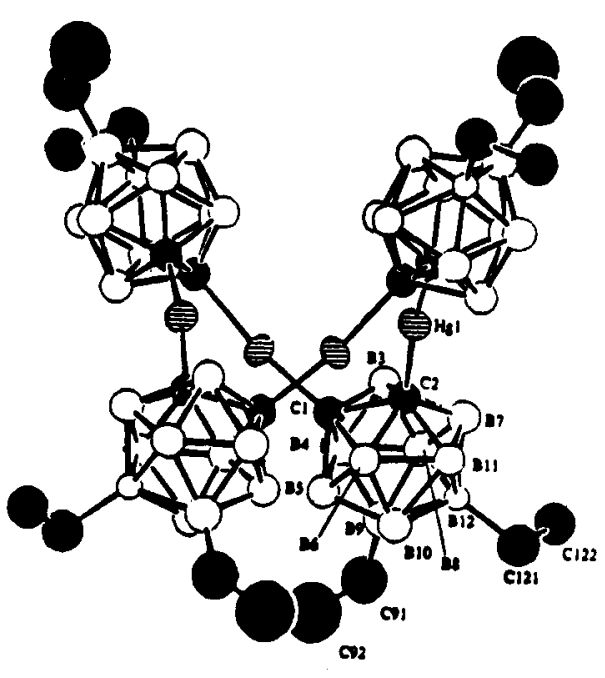

Fig. 5 The molecular structure of 4.

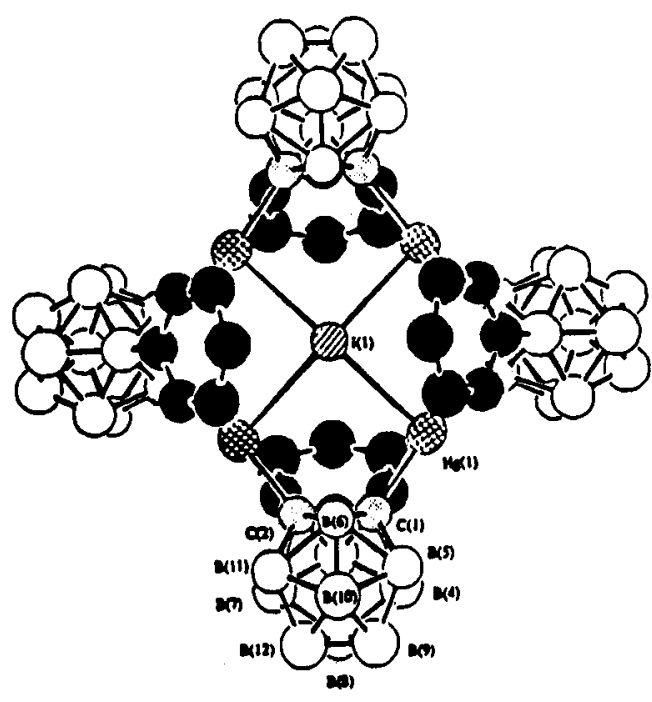

Fig. 6. The molecular structure of $5 \cdot 1$ - 
synthesis is significant since it demonstrates the facile structural modification of the cavity of conformationally immobile mercuracarborand species and portends the creation of chiral complexes and hosts. Preliminary work proves that three isomeric chloride ion complexes of mercuracarborand 5 are formed when $\mathrm{HgCl}_{2}$ was employed as the mercury (II) source.

\section{MERCURY-199 NMR STUDIES}

Mercury-199 NMR spectroscopy has been employed in studies on biological systems and the interactions of organomercurials with a variety of bases and ligands $(18,19)$. The ${ }^{199} \mathrm{Hg}$ nucleus has a spin quantum number of $\mathrm{I}=1 / 2$ and a moderately large natural abundance (16.9\%) (20). The extreme sensitivity of ${ }^{199} \mathrm{Hg}$ chemical shifts to its immediate enviroment make it a very useful probe for the systems we describe here, especially so since mercuracarborands and their anion complexes have very similar ${ }^{13} \mathrm{C}$ and ${ }^{11} \mathrm{~B}$ NMR spectra.

The chemical shifts of mercurcarborands and their complexes range from $-1300 \mathrm{ppm}$ for 1 in THF to $-710 \mathrm{ppm}$ for $3 \cdot \mathrm{I}_{2} \mathrm{Li}_{2}$ in acetone. The chemical shifts of 1,2 and 3 are among the highest field chemical shifts yet reported for diorganomercurials at -1300 in THF, -1221 in $\mathrm{CDCl}_{3}$ and $-1364 \mathrm{ppm}$ in acetone- $d_{6}$, respectively. The complex $1 \cdot \mathrm{ClLi}$ has its resonance at $-1077 \mathrm{ppm}, 1 \cdot \mathrm{BrLi}$ at -1010 ppm and $1 \cdot \mathrm{ILi}$ at $-810 \mathrm{ppm}$ and $1 \cdot \mathrm{I}_{2} \mathrm{Li}_{2}$ at $-714 \mathrm{ppm}$ in acetone, respectively. Similarly, $4 \cdot \mathrm{ILi}$ and $4 \cdot \mathrm{I}_{2} \mathrm{Li}_{2}$ have resonances at -774 and $-674 \mathrm{ppm}$ in acetone, respectively. The downfield shifts which result upon complexation of halide ions to host 1 are $130 \mathrm{ppm}, 200 \mathrm{ppm}$ and $390 \mathrm{ppm}$ for $\mathrm{Cl}, \mathrm{Br}$ and I ions, respectively. Similar downfield shifts were also observed in $\mathrm{RHgX}$ and $\mathrm{HgX}_{2}$ systems, when $\mathrm{RHgX}_{2}-$ and $\mathrm{HgX}_{3}-$ are formed (12). It has been known that ${ }^{199} \mathrm{Hg}$ resonances of organomercurials exhibit large solvent and concentration-dependencies. However, anion complexes of $\mathbf{1}$ and $\mathbf{3}$ have ${ }^{199} \mathrm{Hg}$ chemical shifts which are essentially independent of concentration and solvents at room temperature. We believe that the solid state structures of $1 \cdot X_{n} \operatorname{Li}_{n}(X=C l, B r, n=1 ; X=I, n=1,2)$ and $3 \cdot I_{n} n-(n=1,2)$ remain intact in solution with a planar ring and $\mathrm{Hg}$ atoms pulled towards the center of the tetramer cycle. The carborane cages and halide ions virtually surround the mercury binding sites and it is therefore unlikely that solvent molecules could also coordinate to the $\mathrm{Hg}$ atoms of the tetramer cycle.

Previous studies on halide ion exchange and complexation of mercuric complexes have shown that fast exchange was always observed compared to the NMR time scale (21). The observed resonance exhibits the weighted average of chemical shifts of the several species present in the solution. However, mixtures of $1 \mathrm{ClLi}$ and $1 \cdot \mathrm{BrLi}$ in acetone both exhibit two resonances corresponding to the two individual complexes. Apparently, the exchange between chloride and bromide ions complexed to 1 is too slow to be detected by ${ }^{199} \mathrm{Hg}$ NMR. Similarly, the mixture of 1.ILi and $1 \cdot \mathrm{I}_{2} \mathrm{Li} 2$ displays two resonances. The characteristic ${ }^{199} \mathrm{Hg}$ chemical shift of each of these complexes in solution, independent of solvent and concentration, allows us to study the halide ion exchange and association with 1 in solution, even though more than one species is present.

The conversion of 1 to $1 \cdot \mathrm{I}_{2}{ }^{2-}$ was studied by ${ }^{199} \mathrm{Hg}$ NMR spectroscopy. The incremental addition of $n$-Bu4NI to an acetone- $d_{6}$ solution of 1 results in the formation of $1 \cdot \mathrm{I}^{-}$and then $1 \cdot \mathrm{I}_{2}{ }^{2-}$ after more then one equivalent of $\mathrm{I}^{-}$was added. When two equivalents of $\mathrm{I}^{-}$were added, only one resonance, corresponding to $1 \cdot \mathrm{I}_{2}{ }^{2-}$, remains. When more than two equiv of tetra- $n$-butylammonium iodide were added to the acetone- $\mathrm{d}_{6}$ solution of 1 , no further change in the spectrum was observed, 
indicating that 1 , in agreement with the solid state structure of $1 \cdot \mathrm{I}_{2}{ }^{2-}$, is not capable of hosting more than two iodide ions. This suggests that the solid state structure of $1 \cdot I_{2}{ }^{2-}$ is largely maintained in solution and that $1 \cdot I_{2}{ }^{2-}$ is sufficiently stable that its exchange with bulk halide ions is not observed on NMR-time scale.

\section{SUPRAMOLECULAR CHEMISTRY}

Supramolecular chemistry, the extension of host-guest chemistry, has attracted increasing attention because of its relationship to molecular recognition, catalysis, transport processes, molecular assemblies and the design of supramolecule-based devices (3). Recent work in this area has demonstrated that the successful construction of supramolecular systems is based upon creation of microenvironments with specific features which include both steric and electronic complementarity between host and guest, and the preorganization of those features responsible for complexation.

Closo- $\mathrm{B}_{10} \mathrm{H}_{10} 0^{2-}$ is known to be nucleophilic and to form covalent bonds with Lewis acids such as $\mathrm{Ag}^{+}, \mathrm{Cu}^{+}$and $\mathrm{Hg}^{2+}(22)$. Similarly, we studied the intermolecular interaction of closo- $\mathrm{B}_{10} \mathrm{H}_{10^{2-}}{ }^{2-}(6)$ with [12]-mercuracarborand-4 (1) and its octaethyl derivative (4) in organic solvents (acetone, $\mathrm{CH}_{2} \mathrm{Cl}_{2}$ and $\mathrm{CH}_{3} \mathrm{CN}$ ) using ${ }^{11} \mathrm{~B}$ and ${ }^{199} \mathrm{Hg}$ NMR spectroscopy. The ${ }^{11} \mathrm{~B}$ NMR spectrum of 6 in $\mathrm{CH}_{2} \mathrm{Cl}_{2}$ exhibited two doublets at 0.83 and $-27.3 \mathrm{ppm}$ with a 1:4 ratio, corresponding to axial boron and equatorial boron atoms, respectively. Upon the addition of one equivalent of 1 or 4 in $\mathrm{CH}_{3} \mathrm{CN} / \mathrm{CH}_{2} \mathrm{Cl}_{2}$ (1:1), the doublet at $-27.3 \mathrm{ppm}$ splits into a broad singlet at $-23.3 \mathrm{ppm}$ and a sharp doublet of equal intensity at $-26.9 \mathrm{ppm}$, which can be explained by the formation of adducts of 6 with 1 or 4 in which four equatorial BH groups of 6 bind to four mercury atoms in 1 or 4 .

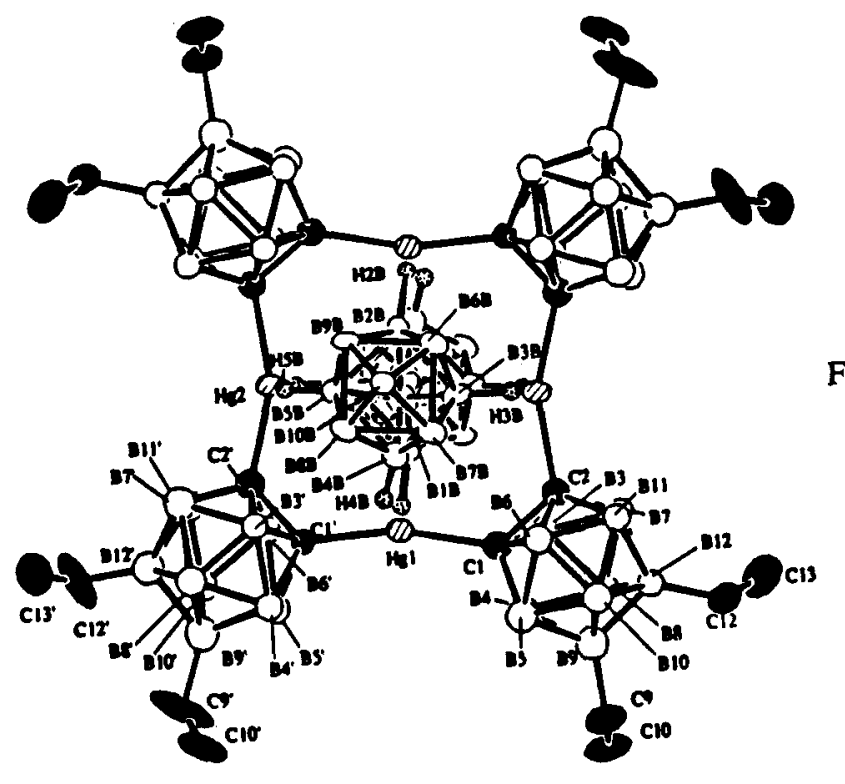

Fig. 7 The molecular structure of $\mathbf{4 \cdot 6 2}$.

The structure of supramolecule $\mathbf{4 \cdot 6 2}$ was deduced from a single crystal X-ray diffraction study, which is shown in Figure 7. The supramolecule consists of a planar macrocyclic tetradentate Lewis acid host and two bicapped square antiprismatic borane cages. As mentioned previously, multiple host-guest binding is known to lead to greater stability of the resulting complexes. The principle of additive binding increments has been applied to explain the enhanced stability of complexes having increased number of binding sites (10) The bonding between 6 and 4 is a four-point-bonding interaction between the host and the guest. The borane dianion binds to 4 through four $\mathrm{B}-\mathrm{H}-\mathrm{-Hg}$ 
intercations. The eight lone-pairs of B-H $\sigma$ bonds are donated to the eight empty p-orbitals of the four $\mathrm{Hg}$ centers. Apparently, these interactions are weak. However, this supramolecule is stable in acetonitrile solution, as detected by ${ }^{11} \mathrm{~B}$ NMR and ${ }^{199} \mathrm{Hg}$ NMR. The stability of the supramolecular aggregates reported here therefore must be due to the cooperative and complementary interactions of the host and guest, noting that planar 1 and 4 both have $C_{4 h}$ symmetry and 6 has $D_{4 d}$ symmetry. It is noteworthy that 1 and 4 do not interact with closo $-\mathrm{B}_{12} \mathrm{H}_{12} 2^{2-}$ or nido-7,9- $\mathrm{C}_{2} \mathrm{~B}_{10} \mathrm{H}_{12}{ }^{1-}$, as revealed by 11B NMR studies. The icosahedral closo- $\mathrm{B}_{12} \mathrm{H}_{12}{ }^{2-}$ is less nucleophilic than 6 , and is sterically incompatible, as well. Consequently, both geometrical and electronic factors may account for the lack of interaction of closo- $\mathrm{B}_{12} \mathrm{H}_{12}$ - and nido-7,9- $\mathrm{C}_{2} \mathrm{~B}_{10} \mathrm{H}_{12}$ - with 1 or 4 .

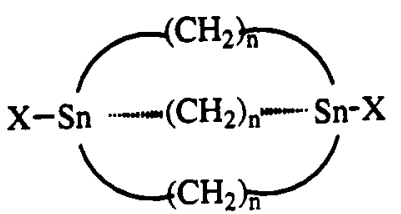

$\mathrm{X}=\mathrm{Cl}, \mathrm{Ph}$

$7 \mathrm{n}=5-10$

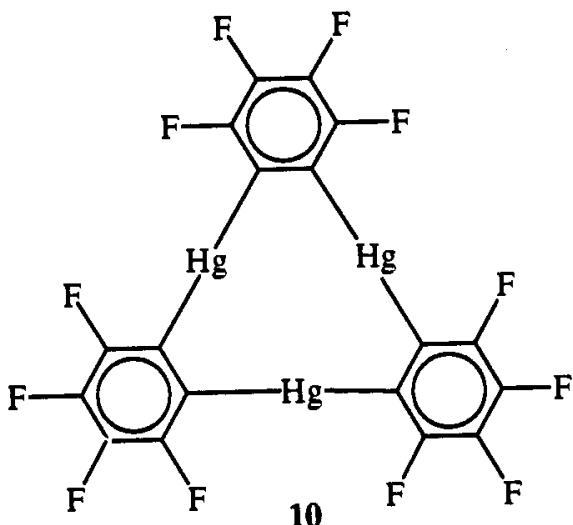

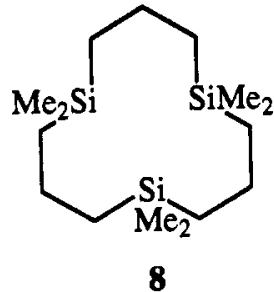
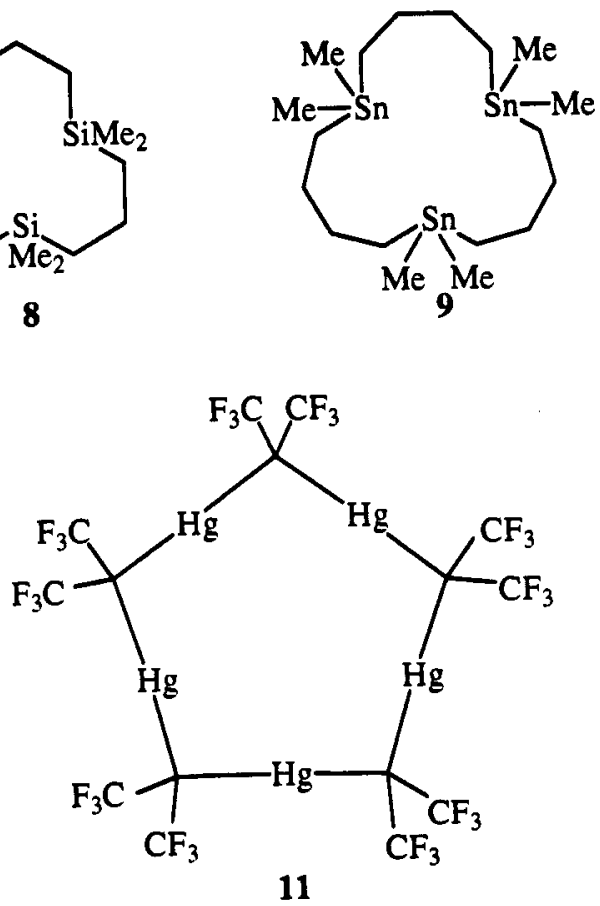

\section{LEWIS ACID HOSTS}

Thus far, several Lewis acid hosts containing tin, silicon, boron and mercury have been synthesized and reported to complex halide ions. Species 7 is a bicyclic host with two tin atoms in bridgehead positions. 8 and 9 are crown ether analogues with Lewis acid binding sites. Even though 8 and 9 each contains three Lewis acid binding sites, there is no evidence that they are actually tridentate hosts. However, 10 and 11 serve as tri- and pentadentate ligands to halide ions (23). Compared with other Lewis acid hosts which contain tin, boron and silicon atoms, mercury centers provide several advantages as Lewis acid binding sites. First, $\mathrm{Hg}$ (II) has a low coordination number and in diorganomercury compounds $\mathrm{Hg}(\mathrm{II})$ forms two linear covalent bonds and has two empty p-orbitals remaining for secondary bonding. Therefore, the hosts 1-4,10 and 11 containing mercury atoms could accommodate more than one guest without too much distortion of the linear coordination of $\mathrm{Hg}$ (II). However, the reported Lewis acids containing tin, boron and silicon could only bind one guest and the coordination geometries of the metals must change dramatically upon complexation of halide ions. 
For example, the Sn(IV) in 1,10-dichloro-1,10-distannabicyclo[8,8,8]hexacosane host has tetrahedral coordination and changes to a trigonal bipyramidal geometry after encrypting a chloride ion (6a). It is obvious that this host-reorganization requires a significant amount of energy. Secondly, the linear geometry around $\mathrm{Hg}$ sites allows the formation of cycles with a larger cavity which can accomodate large guests such as inorganic anions. Only mercury-containing Lewis acids such as 1, 2 and 11 are macrocyclic multidentate hosts. Finally, $\mathrm{Hg}$ (II) species are stable in air and soluble in most organic solvents and it is therefore very convenient to study them.

Since the eariest work of Simmons in 1968 (8a), a series of polycyclic protonated amine hosts have been synthesized. These polycyclic hosts, after protonation, encapsulate anions in their cavity through electrostatic interactions and sometimes multiple hydrogen bonds. Because of the larger size of anions, these hosts must have a large cavity and therefore their synthesis is generally tedious and difficult. Moreover, these hosts are highly charged and the preponderance of them are only soluble in aqueous solution. In comparison, the Lewis acid hosts reported so far are neutral and soluble in organic media, which greatly facilitates their study. Because these hosts contain Lewis acid sites such as $\mathrm{B}, \mathrm{Sn}, \mathrm{Hg}$, multinuclear NMR spectroscopy could be employed in the study of host-guest interactions. While ${ }^{119} \mathrm{Sn}$ NMR has been used in the studies of chloride binding by cycles containing tin atoms (6a), this work demonstrates the appliction of ${ }^{199} \mathrm{Hg} \mathrm{NMR}$ in the studies of anion complexation by 1 and 4 . Moreover, the design and synthesis of mutidentate Lewis acid hosts has opened a new door to host-guest and supramolecular chemistry. The incorporation of Lewis acid-base interactions offers new prospects for anion recognition which is well demonstrated by this work and others (4-7).

Acknowledgement This work was supported by National Science Foundation under the grant CHE-91-11437.

\section{REFERENCES}

(1) Pedersen, C. J. J. Am. Chem. Soc. 89, 7017 (1967).

(2) (a) Cram, D. J. Science 219 , 1177 (1983); (b) Vögtle, F.; Weber, E. Host-Guest Complex Chemistry/Macrocycles; Springer-Verlag: Berlin (1985). (c) Lindoy, L. F. The Chemistry of Macrocyclic Ligands; Cambridge University Press: Cambridge (1989).

(3) (a) Lehn, J.-M. Science, 227, 849 (1985). (b) Lehn, J.-M. Angew. Chem. Int. Ed. Engl. 27, 89 (1989). (c) Lehn, J.-M. Angew. Chem. Int. Ed. Engl. 29, 1304 (1990). (d) Reuter, H. Angew. Chem. Int. Ed. Engl. 31, 1185 (1992). (e) Brienne, M.-J.; Gabard, J.; Lehn, J.-M.; Stibor, I. J. Chem. Soc., Chem. Commun. 1868 (1989). (f) Stupp, S. I.; Son, S.; Lin, H. C.; Li, L. S. Science 259, 59 (1993).

(4) (a) Katz, H. E. Organometallics 6, 1134 (1987). (b) Katz, H. E. J. Am. Chem. Soc. 108, 7640 (1986).

(5) (a) Wuest, J. D.; Zacharie, B. Organometallics 4, 410 (1985). (b) Beauchamp, A. L.; Olivier, M. J.; Wuest, J. D.; Zacharie, B. J. Am. Chem. Soc .108, 73 (1986).

(6) (a) Newcomb, M.; Horner, J. H.; Blanda, M. T.; Squattrito, P. J. J. Am. Chem. Soc. 111, 6294 (1989).

(b) Jurkschat, K.; Kuivila, H. G.; Liu, S.; Zubieta, J. Organometallic 8, 2755 (1989). (c) Jurkschat,

K.; Rühlemann, A.; Tzschach, A. J. Organomet. Chem. 381, C53 (1990).

(7) (a) Jung, M. E.; Xia, H. Tetrahedron Lett. 29, 297 (1988). (b) Tamao, K.; Hayashi, T.; Ito, Y.; Shiro. M. J. Am. Chem. Soc. 112, 2422 (1990). 
(8) (a) Park, C. H.; Simmons, H. E. J. Am. Chem. Soc. 90, 2431 (1968). (b) Bell, R. A.; Christoph, G. G.; Fronczek, F. R.; March, R. E. Science 190, 151 (1975). (c) Vögtle, F.; Sieger, H.; Müller, M. M. In Host Guest Complex Chemistry Macrocycles; Vögtle, F.; Weber, E., Eds.; pp 319-373, SpringerVerlag: Berlin, (1985) and references therein. (d) Dietrich, B.; Lehn, J.-M.; Guilhem, J.; Pascard, C. Tetrahedron Lett. 4125 (1989). (e) Farnham, W. B.; Roe, D. C.; Dixon, D. A.; Calabrese, J. C.; Harlow, R. C. J. Am. Chem. Soc. 112, 7707 (1990). (f) Schmidtchen, F. P.; Gleich, A.; Schummer, A. Pure \& Appl. Chem . 61, 1535 (1989).

(9) Sessler, J. L.; Cyr, M.; Furuta, H.; Kral, V.; Mody, T.; Morishima, T.; Shionoya, M.; Weghorn, S. Pure \& Appl. Chem. 65, 393 (1993) and references therein.

(10) Schneider, H.-J. Angew. Chem. Int. Ed. Engl. 31, 1417 (1992).

(11) (a) Tevault, D.; Strommen, D. P.; Nakamoto, K. J. Am. Chem. Soc. 98, 2998 (1976). (b) Goderey. P. D.; Heffernan, M. L.; Keerr, D. F. Aust. J. Chem. 17, 701(1964).

(12) Goggin, P. L.; Goodfellow, R. J.; Hurst, N. W. J. Chem. Soc. Dalton 561 (1978).

(13) (a) Yang, X.; Knobler, C. B.; Hawthome, M. F. Angew. Chem. Int. Ed. Engl. 30, 1507 (1991). (b) Yang, X; Knobler, C. B.; Hawthorne, M. F. J. Am. Chem. Soc. 114, 380 (1992). (c) Yang, X.; Johnson, S. E.; Kahn, S.; Hawthorne, M. F. Angew. Chem. Int. Ed. Engl. 31, 893 (1992). (d) Yang, X.; Zheng, Z.; Knobler, C. B.; Hawthorne, M. F. J. Am. Chem. Soc. 115, 193 (1993). (e) Yang, X.; Knobler, C, B.; Hawthorne, M. F. J. Am. Chem. Soc. 115, 4904 (1993). (f) Zheng, Z; Yang, X.; Knobler, C, B.; Hawthorne, M. F. J. Am. Chem. Soc. 115, 5320 (1993).

(14) Grimes, R. N. Carboranes ; p. 66, Academic Press: New York; (1970)

(15) Healy, M. D. S.; Rest, A. J. Adv. Inorg. Chem. Radiochem. 21, 1 (1978).

(16) (a) Pauling, L. The Nature of Chemical Bond, 3rd ed.; p.514, Cornell University Press: Ithaca, N. Y., (1960) (b) Bondi, A. J. Phys. Chem. 68, 441 (1964).

(17) Wardell, J. L. Comprehensive Organometallic Chemistry; Wilkinson, G.; Stone, F. G. A.; Abel, E. W., Eds.; Vol. 2, pp 863-978, Pergamon: Oxford, (1982).

(18) (a) Sudmeier, J. L.; Perkins, T. G. J. Am. Chem. Soc. 99, 7732 (1977). (b) Vidusek, D. A.; Robert, M. F.; Bodenhausen, G. J. Am. Chem. Soc. 104, 5452 (1982). (c) Norris, A. R.; Kumar, R. Inorg. Chem. Acta 93, L63 (1984). (d) Bach, R. D.; Vardhan, H. B.; Rahman, A. F. M. M.; Oliver, J. P. Organometallics 4, 846 (1985).

(19) Sen, M. A.; Wilson, N. K.; Ellis, P. D.; Odom, J. D. J. Magn. Resonance 19, 323 (1975).

(20) Kidd, R. G.; Goodfellow, R. J. NMR and the Periodic Table; Harris, R. K.; Mann, B. E., Eds.; pp 195, Academic Press: London; (1978).

(21) (a) Godfrey, P. D.; Heffernan, M. L.; Kerf, D. F. Aust. J. Chem. 17, 701 (1964). (b) Bach, R. D.; Vardhan, H. B. J. Org. Chem. 51, 1609 (1986).

(22) Middaugh, R. L. Boron Hydride Chemistry; Muetterties, E. L., Ed.; p.273, Academic Press: New York, (1975).

(23) (a) Shur, V. B.; Tikhonova, I. A.; Yanovsky, A. I.; Struchkov, Y. T.; Petrovskii, P. V.; Panov.; S. Yu.; Furin, G. G.; Vol'pin, M. E. J. Organomet. Chem. 418, C29 (1991). (b) Shur, V. B.; Tikhonova, I. A.; Dolgushin, F. M.; Yanovsky, A. I.; Struchkov, Y. T.; Volkonsky, A. Yu.; Solodova, E. V.; Panov.; S. Yu.; Petrovskii, P. V.; Vol'pin, M. E. J. Organomet. Chem. 443, C19 (1993). 